With penicillin we observe quite different curves. With high concentrations (100 Oxf. $\mathrm{u} . / \mathrm{cm} .^{3}$ ) proliferation stops almost immediately, followed by a slow lysis of the bacteria ${ }^{2}$; these phenomena seem to be practically independent of the initial concentration of germs. The low concentrations of penicillin $\left(0 \cdot 1-0 \cdot 008\right.$ Oxf. u. $\left./ \mathrm{cm}^{3}\right)$ produce particularly interesting curves (Figs. 3 and 4 ).

We observe that, even for very low concentra. tions, penicillin not only stops the bacterial proliferation in a very short time, but also later shows a very powerful lytic action; the lysis even appears to be more pronounced for higher concentrations.

But if we prolong the recording, a new start of the proliferation is regularly observed (post-lytic growth) followed by a second partial lysis, which is finally followed by a second post-lytic growth. The latter does not appear to be normal, because the final bacterial concentration remains always lower than the test concentration. The results were the same for six different penicillins tested (English, American and French) and correspond to more than fifty curves recorded.

These curves explain the difficulties met with in the titration of penicillin by the dilution method, and the abnormal opacities so often observed when the dilutions are tested photometrically; they probably correspond to the post-lytic proliferation phenomenon. The curves recorded seem to be sufficiently regular, so that we may hope to have a new method of titration by which a given quantity of standard penicillin should be connected with each curve.

1 Bonét-Maury and Walen, Ann. Inst. Pasteur, in the press.

- Nitti, Fossaert and Faguet, Ann. Inst. Pasteur, 70, 80 (1944).

\section{PROF. BORIS KELLER}

\section{By Prof. N. V. TURBIN}

T HE Soviet Government has awarded the Order of the Red Banner of Labour to Prof. Boris Keller as a mark of appreciation of his many years of scientific and pedagogical work. Keller was one of the first Russian botanists to make an ecologophysiological study of the vegetation of the Russian steppes, deserts and semi-arid regions. He aimed at obtaining concrete information on the ways and means by which the evolution of plants takes place in Nature and which lead to their adaptation to differing ecological conditions. He also studied these regions with the view of using them for agricultural purposes.

In studying the flora of the semi-arid regions he made use of his own method of 'ecological series' to study plant associations in connexion with their environment; the method is now widely employed for all phytogeographical work. Keller introduced the conception 'semi-arid region' into the science of phytogeography and was guided by the agrarian peculiarities of these regions as well as by natural and historical features. He compiled one of the best classifications of the steppes and was a pioneer in producing a theory of plant communities, one of the most important divisions of the science.

These investigations are recorded in Keller's works : "In the Semi-Arid Zone", "Botanico-Geographical Research in the Zaisan district of Semipalatinsk Region", "In the Valleys and Mountains of the Altai", "Flora of the Russian Steppes, Deserts and
Semi-Deserts" (1923) and others which are still used in Russian universities as classic examples of phytogeographical research in Russia.

All of Keller's investigations pursued the same object: the all-round study of the plant and the dynamics of its relations to its environment. His ecologo-physiological researches form the complement of his physiogeographical field work.

His work on the imperviousness of plants to droughts and salification have become well known. He regards halophytes and xerophytes ass examples of the ability of plants to adapt themselves to extreme forms of life. Keller revealed the physiological nature of this adaptation in halophytes and xerophytes and produced a picture of the evolution of these ecological forms.

A group of peculiar fleshy halophytes not only thrives in salified soil but also a certain amount of salt in the soil is necessary to enable them to attain full growth and to protect them against unfavourable factors in the environment; this is a confirmation of the theory propounded by Prof. K. A. Timiryazev - to the effect that "plants are capable of converting hostile elements in their environment to their own use".

On the basis of his ecological and geobotanical researches, Keller explained the general laws of the distribution of plants throughout the world and established actual ecological types. To attain this end he has transferred his studies from one branch of botany to another, from classification to anatomy and physiology and back again to classification in order to investigate "the plant as a whole in all the intricate inter-related peculiarities of its structure and the nature of its life".

His direct contact with Nature and ecologophysiological experimentation with living plants strengthened his conviction of the changing nature of plants and the connexion of their properties with the natural conditions with which they have come into contact during their evolution.

Keller is a convinced and consistent protagonist of Darwin's theory of evolution, and his own evolutionary views are based on many years of observations made on plants in their natural surroundings and his research in the sphere of ecology.

The Darwinist nature of his approach to the problems of ecology - the plant, its environment and their interrelations-is the most important feature of Keller's ecological and phytogeographical research. This is what we have in mind when we speak of Keller as an important Russian botanist and Darwinist; this is true of his work in the sphere of phytogeography and the ecology of plants, especially his greatest work, "Fundamentals of the Evolution of Plants", which has been written since the War began. In Keller's works the problems of evolution are first raised as ecologo-physiological problems, whereby they differ from many other important works on evolution which give the greatest importance to morphological methods.

Keller explains the specific features of the evolution of plants on the basis of the ways in which the plants obtain nourishment and their relations with their environment.

$\mathrm{He}$ is of the opinion that the evolution of plants does not depend on casual, isolated mutations but on the selection of those regular changes which first occur in the individual development of the plant as a regular reaction of its adaptive faculties to changes in living conditions and internal relations in the 
plant itself, which then bring about a reconstruction in the progeny in the direction indicated. Environment, therefore, is at once a selective and a formative factor; in these circumstances the formation of a species "as a rule embraces simultaneously many, frequently a very large number of individuals, which are then reformed under the influence of a changing environment or when the plant or a whole family is transferred to a different region"

During recent years Keller has been putting his ideas on the evolution of plants and his conceptions of the fundamental problems of ecology into practice in the Moscow Botanical Gardens of the Academy of Science of the U.S.S.R. which are being built in accordance with his plans.

Prof. Keller is a member of the Academy of Sciences of the U.S.S.R. and the Lenin Academy of Agriculture, director of the Moscow Botanical Gardens and president of the Turkmen Branch of the Academy of Sciences of the U.S.S.R. He takes an active part in public affairs and is a member of the Central Trade Union Council of the U.S.S.R. and of the Executive Committee of the Moscow Regional Soviet.

\section{SOCIAL RELATIONS OF SCIENCE*}

$7 \mathrm{HE}$ advent of peace has led to much discussion on the proper place of science in the post-war world. Different currents of opinion range from the extreme view of the need to suppress science on account of the dangers of its application to war, to that which considers that scientific activities need to be greatly increased and co-ordinated in the interests of providing better conditions of life in Great Britain and throughout the world. Not only is there no agreement as to the amount of science needed, but also considerable divergence of opinion on how science should be organized. Some think of science as "a proper oecupation for the leisure of an English gentleman", and consider that it is more important that it should be completely free and unorganized than that it should be adequately endowed; while others feel that the full value of science can only be reached if it is organized in relation to practical human activities of production, agriculture and health, and can draw on a far larger share of the national income than it has done hitherto. Those who hold the older views have never realized that the relation of science to society is not fixed but continually changes with the growth of science and the increase of complexity of society : what did well in ancient Greece or Victorian England is not appro. priate to the needs of to-day.

Science is not a simple thing; it eludes definition. It is at the same time a professional activity, a body of knowledge, a way of solving problems and an influence on the way in which everyone looks at the world and deals with it. Society is fully entitled to demand that science should be used in solving the problems of providing us with a better standard of living. It would be a very stupid society, however, that attempted to do this without considering the feelings and ideals of scientific workers and the unity of scientific knowledge, which is such that almost any part of it may turn out to bear on almost any other. The Nazis tried to do this : they discouraged fundamental science and generalized thinking and

* Substance of the Trueman Wood Lecture delivered by Prof. J. D. Bernal, F.R.S., before the Royal Society of Arts on May 16. thus, in spite of their enormous technical start, failed in war. Men of science who are taking the responsibilities of science seriously are well aware that a proper proportion of effort must be given to fundamental science which has no immediate application. Out of $£ 24$ millions, which the Association of Scientific Workers suggests should be budgeted for scientific research in Britain, more than $£ 2$ millions would go to fundamental science. The Association is also aware that the actual direction of scientific effort must be in the hands of scientific workers, who alone are competent to know what they are doing.

It is quite possible to plan science, as the example of Britain during the War and the Soviet Union before the War, have shown, in such a way that a continuous link is kept between applied science and fundamental science with a two-way flow of ideasof new ideas coming from fundamental science to be applied, and of problems coming from the applied field, leading to the production of new fundamental theories. The real danger to Great Britain is not that science will be over-organized, but that there will not be nearly enough of organized science. We spend only about one third as much, in proportion, and one tenth in total, as the United States and the Soviet Union on scientific research.

The immediate limiting factor is the number of scientific workers who will be available in the postwar years. With our present educational output, we can never produce scientific workers in adequate numbers; but the importance of this has not been realized, and the additional grants made to the Universities' Grants Committee will scarcely do more than make up for the increased cost of living.

Science is in this situation very largely because its wider influence has never been realized by the public. Science teaching is a belated and unwelcome part of the educational system, and the new Educa. tion Bill has not improved matters. Further, the Press generally treats science only as a purveyor of sensational discoveries.

The War, however, has shown millions of people in the Services and the war factories how important science can be. The very demands which are now being made for adequate food, housing and health are known to be based on scientific studies. The new standards can be achieved only by the application of science. Beyond that, we are beginning to see that not only these problems but also many political and social problems depend on science for their solution. With this realization we may hope will come an increasing emphasis on the balanced development of science, on its increasing use in satisfying social needs and on the spread into ordinary life of a scientific way of thinking and acting.

\section{ISLAND FLORA OF THE GULF OF GUINEA}

$T$ HE three Portuguese islands, S. Tomé, Principe and Annobon, which form the subject of this work* lie, together with Fernando Po, in the Gulf of Guinea. All are of comparatively recent volcanic origin and have a typical equatorial climate with considerable rainfall and very high humidity. Geological evidence and the insular character of their

* Catalogue of the Vascular Plants of S. Tomé (with Principe and Annobon). By Arthur Wallis Exell, and other members of the Department of Botany. Pp. xi +428 . (London: British Museum (Natural History), 1944.) $30 s$. 